This is a post-peer-review, pre-copyedit version of an article published in Metabolic Brain Disease. The final authenticated version is available online at: http://dx.doi.org/10.1007/s11011-014-9573-9

\title{
ELEVATED CEREBRAL LACTATE: IMPLICATIONS IN THE PATHOGENESIS OF HEPATIC ENCEPHALOPATHY
}

\section{Cristina R. Bosoi and Christopher F. Rose}

Hepato-Neuro Laboratory, CRCHUM, Université de Montréal, Québec, Canada

\section{Corresponding author:}

Christopher F. Rose Ph.D.,

Hepato-Neuro Laboratory

Centre Hospitalier de l'Université de Montréal (CRCHUM)

900, rue Saint-Denis - Tour Viger R08.422

Montréal (Québec) H2X 0A9

Université de Montréal, Québec, Canada.

Phone: +1 514890 8000, ext. 35739; email: christopher.rose@ umontreal.ca

Abbreviations: HE, hepatic encephalopathy; MG, methylglyoxal; LDH, lactate dehydrogenase; TCA, tricarboxylic acid cycle; ANLS, astrocyte-neuron lactate shuttle; BBB, blood-brain barrier; MCT, monocarboxylate transporter; ALF, acute liver failure; CLD, chronic liver disease; DCA, dichloroacetate

\section{ABSTRACT}

Hepatic encephalopathy (HE), a complex neuropsychiatric syndrome, is a frequent complication of liver failure/disease.

Increased concentrations of lactate are commonly observed in HE patients, in the systemic circulation, but also in the brain.

Traditionally, increased cerebral lactate is considered a marker of energy failure/impairment however alterations in lactate

homeostasis may also lead to a rise in brain lactate and result in neuronal dysfunction. The latter may involve the

development of brain edema. This review will target the significance of increased cerebral lactate in the pathogenesis of HE. 
This is a post-peer-review, pre-copyedit version of an article published in Metabolic Brain Disease. The final authenticated version is available online at: http://dx.doi.org/10.1007/s11011-014-9573-9

\section{INTRODUCTION}

Lactic acid $\left(\mathrm{CH}_{3}-\mathrm{CH}(\mathrm{OH})-\mathrm{COOH}\right)$ is a carboxylic acid which, in solution, can donate a proton from its carboxyl group, forming the lactate ion $\left(\mathrm{CH}_{3}-\mathrm{CH}(\mathrm{OH})-\mathrm{COO}^{-}\right)$. Lactic acid has two optical isomers: D-lactic acid and its mirror image, $\mathrm{L}-$ lactic acid.

D-lactate is an end-product formed via the glyoxalase system following glutathione-dependent detoxification of methylglyoxal, a highly reactive dicarbonyl compound mainly formed as a by-product of glycolysis. Methylglyoxal is a major precursor of advanced glycation end products, pathogenic factors involved in aging, neurodegenerative disorders and complications of diabetes (Krautwald and Münch 2010). Therefore, D-lactate levels are used as an indicator reflecting activity of the glyoxalase system. In addition, an increase in D-lactate can lead to acidosis as observed in short bowel syndrome or following injections of propylene glycol (a vehicle used for many intravenous medications) (Zosel et al. 2010). It is also believed to play a role in diabetic ketoacidosis (Bo et al. 2013). D-lactate is poorly metabolized in mammalian cells since D-lactate dehydrogenase is solely expressed in mitochondria and has a lower affinity for D-lactate compared to Llactate and its respective dehydrogenase (found in mitochondria and cytosol) (Bélanger et al. 2011). Overall, levels of Dlactate are significantly lower in comparison to L-lactate and its implication in various diseases is poorly described.

L-lactate ${ }^{1}$, the primary focus of this review, is produced in every cell from pyruvate via a reversible reaction catalyzed by the enzyme $\mathrm{LDH}^{2}$, which involves the oxidation of $\mathrm{NADH}$ to $\mathrm{NAD}^{+}$(Figure 1A). Glucose-derived pyruvate (via glycolysis) is a substrate of the tricarboxylic acid (TCA) cycle, the metabolic hub of the cell and final common pathway for the aerobic oxidation of fuel molecules. The conversion of pyruvate to lactate is an active pathway occurring primarily in muscle during anaerobic situations (such as during exercise or hypoxia) which regenerates $\mathrm{NAD}^{+}$needed to sustain the glycolytic pathway. Muscle-derived lactate is metabolized by the liver where it is converted to glucose and used to fuel all organ, including the muscle (Cori cycle) (Woll and Record 1979) (Figure 1B).

\footnotetext{
${ }^{1}$ Throughout the text, "lactate" will represent L-lactate.

${ }^{2}$ Throughout the text, "LDH" will represent L-LDH.
}

Traditionally, glucose is considered the only molecule to fuel the brain; however, new evidence demonstrates that lactate, capable of generating energy (ATP), is a preferred oxidative energy substrate over glucose by neurons (as reviewed by (Pellerin and Magistretti 2012)). The "astrocyte-neuron lactate shuttle" (ANLS) states lactate is primary produced by 
This is a post-peer-review, pre-copyedit version of an article published in Metabolic Brain Disease. The final authenticated version is available online at: http://dx.doi.org/10.1007/s11011-014-9573-9

astrocytes, is released extracellularly and taken up by neurons where it is metabolized and used to fuel the TCA cycle (Schurr 2006; Pellerin et al. 2007). The astrocytes play a major role in regulating the blood-brain barrier (BBB) function as astrocytic end feet wrap around cerebral capillaries; therefore astrocytes are the first cells in the brain exposed to bloodderived glucose. Lactate transporters (monocarboxylate transporters, MCT) are expressed on both astrocytes and neurons. Neuronal MCT2 has a higher affinity than the isoforms MCT1 and MCT4 found in astrocytes (Pierre and Pellerin 2005). LDH also has neuronal and astrocytic isoforms. LDH1 located in neurons has a higher affinity for lactate than the astrocytic LDH5 (Bittar et al. 1996). Therefore, the localization and the dissimilar affinities for lactate of the different isoforms of LDH and MCT in neurons and astrocytes proves that neurons are better equipped to capture and use lactate than astrocytes, therefore sustaining the existence of the ANLS.

\section{LACTATE AND LIVER FAILURE/DISEASE}

Liver disease is an important cause of morbidity and mortality associated with a poor quality of life and a high economic burden (Kim et al. 2002). Impaired liver function arises following acute liver failure (ALF) or chronic liver disease (CLD). ALF, a rapid hepatic necrosis in a previously healthy liver, results in severe deterioration of the clinical status and the apparition of jaundice, encephalopathy and coagulopathy. CLD is a long-term progressive loss of hepatic function leading to cirrhosis which is characterized histologically by fibrosis and regenerative nodules. ALF and CLD consequently lead to numerous metabolic disturbances and to an increase in circulating toxins affecting distant organs including the brain.

Hepatic encephalopathy (HE) is a major complication of both ALF and CLD which includes a large spectrum of neurological symptoms, ranging from mild attention, memory and psychomotor disturbances to extrapyramidal symptoms, tremor, ataxia, stupor and coma (Hartmann et al. 2000; Bajaj et al. 2007). An important entity of both ALF and CLD is the presence of brain edema (Rose et al. 2007; Cauli et al. 2011; Bosoi et al. 2014) with intracranial hypertension leading to $25 \%$ mortality in ALF patients (Lee 1993).

\section{HYPERLACTATEMIA IN LIVER FAILURE/DISEASE}

Hyperlactataemia has been described in various animal models of ALF (Chatauret et al. 2003; Rose et al. 2007) and has been established as a prognostic marker in patients with ALF (Bernal et al. 2002). In CLD, blood lactate levels increase with the severity of cirrhosis (Jeppesen et al. 2013) and are associated with mortality in severe patients (Zauner et al. 2000; Tas et al. 2012). Several mechanisms are implicated in the onset of hyperlactatemia during ALF/CLD: (i) decreased hepatic lactate 
This is a post-peer-review, pre-copyedit version of an article published in Metabolic Brain Disease. The final authenticated version is available online at: http://dx.doi.org/10.1007/s11011-014-9573-9

metabolism due to hepatocyte loss (i.e interrupted Cori cycle) (Woll and Record 1979; Levraut et al. 1998), (ii) increased lactate release from necrotic hepatocytes (Clemmesen et al. 2000); or (iii) increased extra-hepatic lactate production following multi-organ-failure (Bernal et al. 2002).

\section{SOURCE OF INCREASED LACTATE IN BRAIN IN LIVER FAILURE/DISEASE}

Increased brain lactate is commonly observed in HE. In ALF, it has been evidenced by cerebral microdialysis studies in patients (Tofteng et al. 2002; Bjerring et al. 2010) as well as in animal models (Chatauret et al. 2003; Rose et al. 2007; Chavarria et al. 2010). Increased cerebral lactate is strongly correlated with an increase in intracranial pressure (Tofteng et al. 2002; Rose et al. 2007; Bjerring et al. 2008). In CLD, only one clinical study (16 cirrhotic patients) showed an increase in brain lactate (cerebrospinal fluid) (Yao et al. 1987). However, recently our group demonstrated an increase in cerebral lactate in cirrhotic rats was found to play a major role in the pathogenesis of brain edema (Bosoi et al. 2014).

Although increased plasma lactate has been evidenced in ALF and CLD patients, in the context of HE, it is unresolved whether systemic lactate is a source for increased cerebral lactate. Even though the BBB, which strictly controls the flow of molecules into the brain, has been shown to express MCT1 on cerebral endothelial cells (Pierre and Pellerin 2005), lactate has been shown not to easily cross an intact BBB (Hertz and Dienel 2002). Clearly, a breakdown of the BBB would facilitate the entry of lactate into the brain which has been evidenced in animals models of ALF: extravasation into the brain of Evans Blue and $\left[{ }^{14} \mathrm{C}\right]$ alpha-aminoisobutyric acid as well as modifications in the expression of BBB tight junction proteins have been observed in ALF (Yamamoto and Nguyen 2006; Sawara et al. 2009; Chen et al. 2009; Cauli et al. 2011). However, in CLD, the BBB seems to remain intact (Wright et al. 2007; Bosoi et al. 2012). Nevertheless, studies involving animal models of ALF and CLD and using nuclear magnetic resonance (NMR) and ${ }^{13} \mathrm{C}$-glucose, showed an increase in local production of cerebral lactate (Zwingmann et al. 2003; Bosoi et al. 2014). Since neuronal cell death is not described as a cardinal feature of $\mathrm{HE}$, an increase in cerebral lactate is believed not to be a result of energy failure but instead is defined as impairment in cellular energy metabolism (Zwingmann 2007). This is supported by studies showing HE induced by acute ammonia infusion or by ALF does not lead to a decrease in ATP (Lin and Raabe 1985; Fitzpatrick et al. 1989; Mans et al. 1994). However, increased lactate represents more than just a marker reflecting metabolic impairment as elevated levels of brain lactate can also lead to lactic acidosis which can cause adverse cellular effects (Kaila and Ransom 1998). Therefore, an increase in cerebral lactate may be a marker of energy impairment which consequently causes neurological impairment or may directly cause cerebral dysfunction and HE. 
This is a post-peer-review, pre-copyedit version of an article published in Metabolic Brain Disease. The final authenticated version is available online at: http://dx.doi.org/10.1007/s11011-014-9573-9

\section{INCREASED CEREBRAL LACTATE - ALTERED HOMEOSTASIS?}

Cerebral lactate homeostasis is maintained between lactate production/metabolism as well as release/uptake between astrocytes and neurons. This balance is important for the proper function of ANLS and metabolic impairment and/or transporter dysfunction can lead to alterations in lactate homeostasis and cellular dysfunction. Numerous microdialysis studies evidenced an increase in lactate levels in the extracellular compartment of the brain during ALF-induced HE (Tofteng et al. 2002; Rose et al. 2007). This may be due to either an increase in astrocyte production and release or, a decrease in neuronal uptake and metabolism. Total brain (astrocyte and neuronal) LDH activity was increased in pigs with ALF induced by hepatic devascularisation. However the specific activity of each LDH isoform was investigated. In anycase, the LDH activity increase persisted following treatment with molecular adsorbent recirculation system in spite of a significant reduction in extracellular cerebral lactate levels (Rose et al. 2007), suggesting a higher need for lactate is required during conditions of $\mathrm{HE}$. However, non-treated animals are unable to consume the increased lactate leading to increased extracellular levels which diminish following treatment. The role of each LDH isoform (astrocytic and neuronal) as well as expression of specific MCTs remains unknown and alterations in ANLS merits investigation in the pathogenesis of HE.

\section{LACTATE AND NEURONAL DEATH}

Increased cerebral lactate has been described in numerous neurological diseases like ischemia/infarction but also cerebral tumors, acute seizures, cerebral infectious and inflammatory diseases (abscesses, progressive multifocal leukoencephalopathy, acute disseminated encephalomyelitis, encephalitis), multiple sclerosis, metabolic disorders affecting lipid, carbohydrate, amino acid metabolism or the mitochondria (for review see (Shih et al. 2004)). In the majority of these conditions, neuronal death is frequently observed (Gorman 2008; Languren et al. 2013; Baron et al. 2014).

Given that HE is a metabolic syndrome, it is defined as "reversible" following the treatment of the diseased liver or following a liver transplantation. Therefore, for many decades, there has been very little reason to speculate neuronal cell death occurs in HE. However, with recent observations demonstrating the existence of persisting neurological complications following liver transplantation (Ciancio et al. 2002; Amodio et al. 2007; Sotil et al. 2009; Atluri et al. 2010), the conception of neuronal cell death in HE deserves to be be revisited. In addition, there is some evidence depicting a decrease in ATP is associated with severe HE (Hindfelt et al. 1977), a finding which supports the observations that severe HE (or episodes of 
This is a post-peer-review, pre-copyedit version of an article published in Metabolic Brain Disease. The final authenticated version is available online at: http://dx.doi.org/10.1007/s11011-014-9573-9

severe HE) pre-liver transplantation significantly impact neurological outcome following liver transplantation (Sotil et al. 2009). Furthermore, as many neurodegenerative diseases are associated with increased brain lactate, this provides further reasoning to pursue the role of neuronal cell death in HE. It is possible, neuronal cell death may only occur under certain liver-induced pathological conditions, including the etiological cause of the disease (Butterworth et al. 1993; Butterworth 2007) or severity of HE (Hindfelt et al. 1977; Therrien et al. 1997). This is an important field of research which merits to be thoroughly investigated.

\section{AMMONIA AND LACTATE RELATIONSHIP}

Ammonia has long been considered the main factor involved in the pathogenesis of HE. Ammonia has been demonstrated to increase glycolysis by stimulating the enzyme phosphofructokinase (Lowry and Passonneau 1966), but has also shown to reduce $\alpha$-ketoglutarate dehydrogenase activity, the rate-limiting enzyme of the TCA cycle (Lai and Cooper 1986). Therefore ammonia toxicity affects energy metabolism and subsequently leads to an increase in brain lactate (Bosman et al. 1990). In fact, acute ammonia injection in normal and portacaval shunted rats led to an increase in brain lactate (Fitzpatrick et al. 1989; Therrien et al. 1997). Moreover, NMR studies evidenced lactate synthesis is dependent on the concentration of ammonia (Zwingmann et al. 2003; Bosoi et al. 2014) and various therapeutic interventions aimed at reducing ammonia such as hypothermia, albumin dialysis, AST-120 (spherical carbon adsorbent) and L-ornithine L-aspartate, have led to a significant reduction in cerebral lactate levels (Vogels et al. 1997; Chatauret et al. 2003; Rose et al. 2007; Bosoi et al. 2014). Two particular studies involving; (i) pigs with ALF (induced by liver devascularisation) and (ii) rats with CLD (induced following bile-duct ligation) demonstrated strong correlations between cerebral ammonia and lactate levels (Figure 2, (Rose et al. 2007; Bosoi et al. 2014)).

Since the direct effects of ammonia toxicity can lead to numerous pathological consequences such as impaired mRNA and protein expression, calcium signaling or inducing oxidative stress (Rose, 2005; Perazzo 2012), altered protein structure and function may ensue (Stadtman and Levine 2000). To this regard, whether increased ammonia affects lactate homeostasis by modulating lactate transporters or enzymes remains to be elucidated in the future. 
This is a post-peer-review, pre-copyedit version of an article published in Metabolic Brain Disease. The final authenticated version is available online at: http://dx.doi.org/10.1007/s11011-014-9573-9

\section{ROLE OF LACTATE IN BRAIN EDEMA (ALF AND CLD)}

There is accumulating evidence that lactate plays an important role in the development of brain edema during ALF or CLD as previously reviewed (Bosoi and Rose 2013). Lactate is known to induce astrocyte swelling in vitro (Staub et al. 1990) and is associated with the development of brain edema in animal models of ALF (Zwingmann et al. 2003; Chatauret et al. 2003; Sen et al. 2006; Chavarria et al. 2010). Furthermore, in patients with ALF, an increase in extracellular brain lactate was found to correlate with increased intracranial pressure (Tofteng et al. 2002). In addition to lactate playing a major role in the development of brain edema in ALF, we demonstrated that in CLD, increased cerebral lactate also induces brain edema in bile duct ligated rats (Bosoi et al. 2014). Overall, the mechanisms by which lactate induces brain edema in the pathogenesis of HE remain unknown. However, it has been speculated that alterations in lactate homeostasis can lead to lactate-induced osmotic changes and hence cell swelling (Preuss 2012).

\section{TREATMENTS FOR HE: TARGETING LACTATE?}

Recently, our group tested the effect of dichloroacetate (DCA) (lactate synthesis inhibitor) on the development of brain edema in bile-duct ligated rats and we found a reduction in cerebral lactate resulted in a decrease in brain edema (Bosoi et al. 2014). DCA treatment did not have an effect on degree of hyperammonemia or on hepatic function. This concludes lactate (possibly as a result from ammonia toxicity) plays an important role in the development of brain edema. DCA reduces lactate synthesis by inhibiting PDH kinase (which normally phosphorylates and inactivates PDH) activity. In turn, pyruvate entry into the TCA cycle is increased and less lactate is generated (Figure 3, (Stacpoole et al. 1998)). DCA has been successfully used in patients for the treatment of various tumors as a metabolic modulator, since cancer cells have a high rate of glycolysis followed by lactic acid fermentation in the cytosol (Kumar et al. 2013). DCA has also been shown beneficial in other diseases such as congenital lactic acidosis (Abdelmalak et al. 2013) and chronic obstructive pulmonary disease (Calvert et al. 2008); in these conditions it proved to be safe following long-term administration with no adverse reactions. Therefore, in addition to investigating into novel ammonia lowering strategies for the treatment of HE (Rose 2012), innovative approaches to reduce lactate is a therapeutic avenue which deserves to be further studied. DCA is safe and effective in attenuating increased cerebral lactate and therefore merits to be tested for the treatment of $\mathrm{HE}$ in patients with either ALF or CLD. 
This is a post-peer-review, pre-copyedit version of an article published in Metabolic Brain Disease. The final authenticated version is available online at: http://dx.doi.org/10.1007/s11011-014-9573-9

\section{CONCLUSIONS}

Cerebral lactate is commonly increased in patients with HE in both the context of ALF or CLD. An increase in brain lactate may reflect energy failure/impairment and/or alterations in lactate homeostasis. In addition, elevated levels of lactate may induce cellular dysfunction/death through lactic acidosis. In all cases, disturbances in ANLS (and hence alterations in lactate homeostasis) may be involved which remains poorly understood in the pathogenesis of HE. Increased cerebral lactate is associated with various neurodegenerative diseases and therefore neuronal cell death in HE merits to be revisited. The strong correlation between ammonia and lactate supports ammonia-lowering strategies remain at the forefront for the treatment of HE however directly attenuating increased lactate represents an therapeutic option which merits to be further investigated in patients with HE.

\section{REFERENCES}

Abdelmalak M, Lew A, Ramezani R, et al. (2013) Long-term safety of dichloroacetate in congenital lactic acidosis. Mol Genet Metab 109:139-143. doi: 10.1016/j.ymgme.2013.03.019

Amodio P, Biancardi A, Montagnese S, et al. (2007) Neurological complications after orthotopic liver transplantation. Dig Liver Dis Off J Ital Soc Gastroenterol Ital Assoc Study Liver 39:740-747. doi: 10.1016/j.dld.2007.05.004

Atluri DK, Asgeri M, Mullen KD (2010) Reversibility of hepatic encephalopathy after liver transplantation. Metab Brain Dis 25:111-113. doi: 10.1007/s11011-010-9178-x

Bajaj JS, Saeian K, Verber MD, et al. (2007) Inhibitory control test is a simple method to diagnose minimal hepatic encephalopathy and predict development of overt hepatic encephalopathy. Am J Gastroenterol 102:754-760. doi: 10.1111/j.1572-0241.2007.01048.x

Baron J-C, Yamauchi H, Fujioka M, Endres M (2014) Selective neuronal loss in ischemic stroke and cerebrovascular disease. J Cereb Blood Flow Metab Off J Int Soc Cereb Blood Flow Metab 34:2-18. doi: 10.1038/jcbfm.2013.188

Bélanger M, Yang J, Petit J-M, et al. (2011) Role of the glyoxalase system in astrocyte-mediated neuroprotection. J Neurosci Off J Soc Neurosci 31:18338-18352. doi: 10.1523/JNEUROSCI.1249-11.2011

Bernal W, Donaldson N, Wyncoll D, Wendon J (2002) Blood lactate as an early predictor of outcome in paracetamolinduced acute liver failure: a cohort study. The Lancet 359:558-563. doi: 10.1016/S0140-6736(02)07743-7

Bittar PG, Charnay Y, Pellerin L, et al. (1996) Selective distribution of lactate dehydrogenase isoenzymes in neurons and astrocytes of human brain. J Cereb Blood Flow Metab Off J Int Soc Cereb Blood Flow Metab 16:1079-1089. doi: 10.1097/00004647-199611000-00001

Bjerring PN, Hauerberg J, Frederiksen H-J, et al. (2008) Cerebral glutamine concentration and lactate-pyruvate ratio in patients with acute liver failure. Neurocrit Care 9:3-7. doi: 10.1007/s12028-008-9060-4

Bjerring PN, Hauerberg J, Jørgensen L, et al. (2010) Brain hypoxanthine concentration correlates to lactate/pyruvate ratio but not intracranial pressure in patients with acute liver failure. J Hepatol 53:1054-1058. doi:

10.1016/j.jhep.2010.05.032 
This is a post-peer-review, pre-copyedit version of an article published in Metabolic Brain Disease. The final authenticated version is available online at: http://dx.doi.org/10.1007/s11011-014-9573-9

Bo J, Li W, Chen Z, et al. (2013) D-lactate: a novel contributor to metabolic acidosis and high anion gap in diabetic ketoacidosis. Clin Chem 59:1406-1407. doi: 10.1373/clinchem.2013.208777

Bosman DK, Deutz NE, De Graaf AA, et al. (1990) Changes in brain metabolism during hyperammonemia and acute liver failure: results of a comparative 1H-NMR spectroscopy and biochemical investigation. Hepatol Baltim Md 12:281-290.

Bosoi CR, Rose CF (2013) Brain edema in acute liver failure and chronic liver disease: similarities and differences. Neurochem Int 62:446-457. doi: 10.1016/j.neuint.2013.01.015

Bosoi CR, Yang X, Huynh J, et al. (2012) Systemic oxidative stress is implicated in the pathogenesis of brain edema in rats with chronic liver failure. Free Radic Biol Med 52:1228-1235. doi: 10.1016/j.freeradbiomed.2012.01.006

Bosoi CR, Zwingmann C, Marin H, et al. (2014) Increased brain lactate is central to the development of brain edema in rats with chronic liver disease. J Hepatol 60:554-560. doi: 10.1016/j.jhep.2013.10.011

Butterworth RF (2007) Neuronal cell death in hepatic encephalopathy. Metab Brain Dis 22:309-320. doi: 10.1007/s11011007-9072-3

Butterworth RF, Kril JJ, Harper CG (1993) Thiamine-dependent enzyme changes in the brains of alcoholics: relationship to the Wernicke-Korsakoff syndrome. Alcohol Clin Exp Res 17:1084-1088.

Calvert LD, Shelley R, Singh SJ, et al. (2008) Dichloroacetate enhances performance and reduces blood lactate during maximal cycle exercise in chronic obstructive pulmonary disease. Am J Respir Crit Care Med 177:1090-1094. doi: $10.1164 / \mathrm{rccm} .200707-1032 \mathrm{OC}$

Cauli O, López-Larrubia P, Rodrigo R, et al. (2011) Brain region-selective mechanisms contribute to the progression of cerebral alterations in acute liver failure in rats. Gastroenterology 140:638-645. doi: 10.1053/j.gastro.2010.10.043

Chatauret N, Zwingmann C, Rose C, et al. (2003) Effects of hypothermia on brain glucose metabolism in acute liver failure: a H/C-nuclear magnetic resonance study. Gastroenterology 125:815-824.

Chavarria L, Oria M, Romero-Gimenez J, et al. (2010) Diffusion tensor imaging supports the cytotoxic origin of brain edema in a rat model of acute liver failure. Gastroenterology 138:1566-1573. doi: 10.1053/j.gastro.2009.10.003

Chen F, Ohashi N, Li W, et al. (2009) Disruptions of occludin and claudin-5 in brain endothelial cells in vitro and in brains of mice with acute liver failure. Hepatol Baltim Md 50:1914-1923. doi: 10.1002/hep.23203

Ciancio A, Marchet A, Saracco G, et al. (2002) Spectral electroencephalogram analysis in hepatic encephalopathy and liver transplantation. Liver Transplant Off Publ Am Assoc Study Liver Dis Int Liver Transplant Soc 8:630-635. doi: $10.1053 /$ jlts.2002.33971

Clemmesen JO, Høy CE, Kondrup J, Ott P (2000) Splanchnic metabolism of fuel substrates in acute liver failure. J Hepatol 33:941-948.

Fitzpatrick SM, Hetherington HP, Behar KL, Shulman RG (1989) Effects of acute hyperammonemia on cerebral amino acid metabolism and pHi in vivo, measured by $1 \mathrm{H}$ and 31P nuclear magnetic resonance. J Neurochem 52:741-749.

Gorman AM (2008) Neuronal cell death in neurodegenerative diseases: recurring themes around protein handling. J Cell Mol Med 12:2263-2280. doi: 10.1111/j.1582-4934.2008.00402.x

Hartmann IJ, Groeneweg M, Quero JC, et al. (2000) The prognostic significance of subclinical hepatic encephalopathy. Am J Gastroenterol 95:2029-2034. doi: 10.1111/j.1572-0241.2000.02265.x 
This is a post-peer-review, pre-copyedit version of an article published in Metabolic Brain Disease. The final authenticated version is available online at: http://dx.doi.org/10.1007/s11011-014-9573-9

Hertz L, Dienel GA (2002) Energy metabolism in the brain. Int Rev Neurobiol 51:1-102.

Hindfelt B, Plum F, Duffy TE (1977) Effect of acute ammonia intoxication on cerebral metabolism in rats with portacaval shunts. J Clin Invest 59:386-396. doi: 10.1172/JCI108651

Jeppesen JB, Mortensen C, Bendtsen F, Møller S (2013) Lactate metabolism in chronic liver disease. Scand J Clin Lab Invest. doi: 10.3109/00365513.2013.773591

Jiménez B, Montoliu C, MacIntyre DA, et al. (2010) Serum metabolic signature of minimal hepatic encephalopathy by (1)H-nuclear magnetic resonance. J Proteome Res 9:5180-5187. doi: 10.1021/pr100486e

Kaila K, Ransom BR (1998) pH and brain function. Wiley-Liss, New York

Kim WR, Brown RS Jr, Terrault NA, El-Serag H (2002) Burden of liver disease in the United States: summary of a workshop. Hepatol Baltim Md 36:227-242. doi: 10.1053/jhep.2002.34734

Krautwald M, Münch G (2010) Advanced glycation end products as biomarkers and gerontotoxins - A basis to explore methylglyoxal-lowering agents for Alzheimer's disease? Exp Gerontol 45:744-751. doi: 10.1016/j.exger.2010.03.001

Kumar A, Kant S, Singh SM (2013) Antitumor and chemosensitizing action of dichloroacetate implicates modulation of tumor microenvironment: a role of reorganized glucose metabolism, cell survival regulation and macrophage differentiation. Toxicol Appl Pharmacol 273:196-208. doi: 10.1016/j.taap.2013.09.005

Lai JC, Cooper AJ (1986) Brain alpha-ketoglutarate dehydrogenase complex: kinetic properties, regional distribution, and effects of inhibitors. J Neurochem 47:1376-1386.

Languren G, Montiel T, Julio-Amilpas A, Massieu L (2013) Neuronal damage and cognitive impairment associated with hypoglycemia: An integrated view. Neurochem Int 63:331-343. doi: 10.1016/j.neuint.2013.06.018

Lee WM (1993) Acute Liver Failure. N Engl J Med 329:1862-1872. doi: 10.1056/NEJM199312163292508

Levraut J, Ciebiera JP, Chave S, et al. (1998) Mild hyperlactatemia in stable septic patients is due to impaired lactate clearance rather than overproduction. Am J Respir Crit Care Med 157:1021-1026. doi:

10.1164/ajrccm.157.4.9705037

Lin S, Raabe W (1985) Ammonia intoxication: effects on cerebral cortex and spinal cord. J Neurochem 44:1252-1258.

Lowry OH, Passonneau JV (1966) Kinetic evidence for multiple binding sites on phosphofructokinase. J Biol Chem 241:2268-2279.

Mans AM, DeJoseph MR, Hawkins RA (1994) Metabolic abnormalities and grade of encephalopathy in acute hepatic failure. J Neurochem 63:1829-1838.

Pellerin L, Bouzier-Sore A-K, Aubert A, et al. (2007) Activity-dependent regulation of energy metabolism by astrocytes: an update. Glia 55:1251-1262. doi: 10.1002/glia.20528

Pellerin L, Magistretti PJ (2012) Sweet sixteen for ANLS. J Cereb Blood Flow Metab Off J Int Soc Cereb Blood Flow Metab 32:1152-1166. doi: 10.1038/jcbfm.2011.149

Perazzo JC (2012) Hepatic encephalopathy: An approach to its multiple pathophysiological features. World J Hepatol 4:50. doi: 10.4254/wjh.v4.i3.50 
This is a post-peer-review, pre-copyedit version of an article published in Metabolic Brain Disease. The final authenticated version is available online at: http://dx.doi.org/10.1007/s11011-014-9573-9

Pierre K, Pellerin L (2005) Monocarboxylate transporters in the central nervous system: distribution, regulation and function. J Neurochem 94:1-14. doi: 10.1111/j.1471-4159.2005.03168.x

Preuss M (2012) An energy-failure based brain edema concept. Med Hypotheses 79:259-260. doi: 10.1016/j.mehy.2012.05.003

Rose C, Kresse W, Kettenmann H (2005) Acute insult of ammonia leads to calcium-dependent glutamate release from cultured astrocytes, an effect of pH. J Biol Chem. 3;280(22):20937-44

Rose C, Ytrebø LM, Davies NA, et al. (2007) Association of reduced extracellular brain ammonia, lactate, and intracranial pressure in pigs with acute liver failure. Hepatol Baltim Md 46:1883-1892. doi: 10.1002/hep.21877

Rose, C (2012) Ammonia-lowering strategies for the treatment of hepatic encephalopathy. Clin Pharmacol Ther. 92(3):32131. doi: $10.1038 /$ clpt.2012.112

Sawara K, Desjardins P, Chatauret N, et al. (2009) Alterations in expression of genes coding for proteins of the neurovascular unit in ischemic liver failure. Neurochem Int 55:119-123. doi: 10.1016/j.neuint.2009.01.023

Schurr A (2006) Lactate: the ultimate cerebral oxidative energy substrate? J Cereb Blood Flow Metab Off J Int Soc Cereb Blood Flow Metab 26:142-152. doi: 10.1038/sj.jcbfm.9600174

Sen S, Rose C, Ytrebø LM, et al. (2006) Effect of albumin dialysis on intracranial pressure increase in pigs with acute liver failure: a randomized study. Crit Care Med 34:158-164.

Shih MT, Singh AK, Wang A-M, Patel S (2004) Brain lesions with elevated lactic acid peaks on magnetic resonance spectroscopy. Curr Probl Diagn Radiol 33:85-95. doi: 10.1016/j.cpradiol.2003.11.002

Sotil EU, Gottstein J, Ayala E, et al. (2009) Impact of preoperative overt hepatic encephalopathy on neurocognitive function after liver transplantation. Liver Transplant Off Publ Am Assoc Study Liver Dis Int Liver Transplant Soc 15:184192. doi: $10.1002 / 1 \mathrm{t} .21593$

Stacpoole PW, Henderson GN, Yan Z, James MO (1998) Clinical pharmacology and toxicology of dichloroacetate. Environ Health Perspect 106 Suppl 4:989-994.

Stadtman ER, Levine RL (2000) Protein oxidation. Ann N Y Acad Sci 899:191-208.

Staub F, Baethmann A, Peters J, et al. (1990) Effects of lactacidosis on glial cell volume and viability. J Cereb Blood Flow Metab Off J Int Soc Cereb Blood Flow Metab 10:866-876.

Tas A, Akbal E, Beyazit Y, Kocak E (2012) Serum lactate level predict mortality in elderly patients with cirrhosis. Wien Klin Wochenschr 124:520-525. doi: 10.1007/s00508-012-0208-Z

Therrien G, Rose C, Butterworth J, Butterworth RF (1997) Protective effect of L-carnitine in ammonia-precipitated encephalopathy in the portacaval shunted rat. Hepatol Baltim Md 25:551-556. doi: 10.1002/hep.510250310

Tofteng F, Jorgensen L, Hansen BA, et al. (2002) Cerebral microdialysis in patients with fulminant hepatic failure. Hepatol Baltim Md 36:1333-1340. doi: 10.1053/jhep.2002.36944

Vogels BA, Karlsen OT, Mass MA, et al. (1997) L-ornithine vs. L-ornithine-L-aspartate as a treatment for hyperammonemia-induced encephalopathy in rats. J Hepatol 26:174-182.

Woll PJ, Record CO (1979) Lactate elimination in man: effects of lactate concentration and hepatic dysfunction. Eur J Clin Invest 9:397-404. 
This is a post-peer-review, pre-copyedit version of an article published in Metabolic Brain Disease. The final authenticated version is available online at: http://dx.doi.org/10.1007/s11011-014-9573-9

Wright G, Davies NA, Shawcross DL, et al. (2007) Endotoxemia produces coma and brain swelling in bile duct ligated rats. Hepatol Baltim Md 45:1517-1526. doi: 10.1002/hep.21599

Yamamoto S, Nguyen JH (2006) TIMP-1/MMP-9 imbalance in brain edema in rats with fulminant hepatic failure. J Surg Res 134:307-314. doi: 10.1016/j.jss.2005.11.588

Yao H, Sadoshima S, Fujii K, et al. (1987) Cerebrospinal fluid lactate in patients with hepatic encephalopathy. Eur Neurol 27:182-187.

Zauner C, Schneeweiss B, Schneider B, et al. (2000) Short-term prognosis in critically ill patients with liver cirrhosis: an evaluation of a new scoring system. Eur J Gastroenterol Hepatol 12:517-522.

Zosel A, Egelhoff E, Heard K (2010) Severe lactic acidosis after an iatrogenic propylene glycol overdose. Pharmacotherapy 30:219. doi: 10.1592/phco.30.2.219

Zwingmann C (2007) Nuclear magnetic resonance studies of energy metabolism and glutamine shunt in hepatic encephalopathy and hyperammonemia. J Neurosci Res 85:3429-3442. doi: 10.1002/jnr.21445

Zwingmann C, Chatauret N, Leibfritz D, Butterworth RF (2003) Selective increase of brain lactate synthesis in experimental acute liver failure: results of a $[\mathrm{H}-\mathrm{C}]$ nuclear magnetic resonance study. Hepatol Baltim Md 37:420428. doi: 10.1053/jhep.2003.50052 
This is a post-peer-review, pre-copyedit version of an article published in Metabolic Brain Disease. The final authenticated version is available online at: http://dx.doi.org/10.1007/s11011-014-9573-9

\section{FIGURE LEGENDS}

A

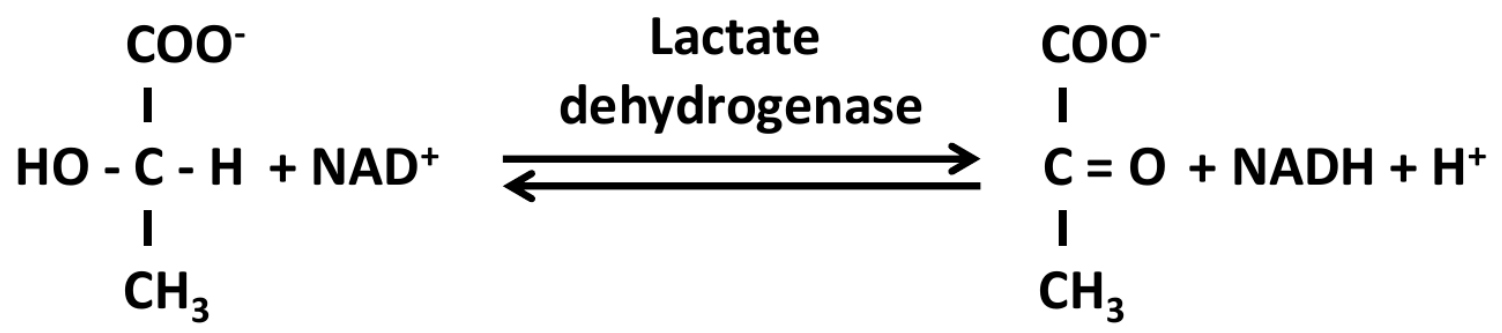

Lactate $\quad$ Pyruvate

B

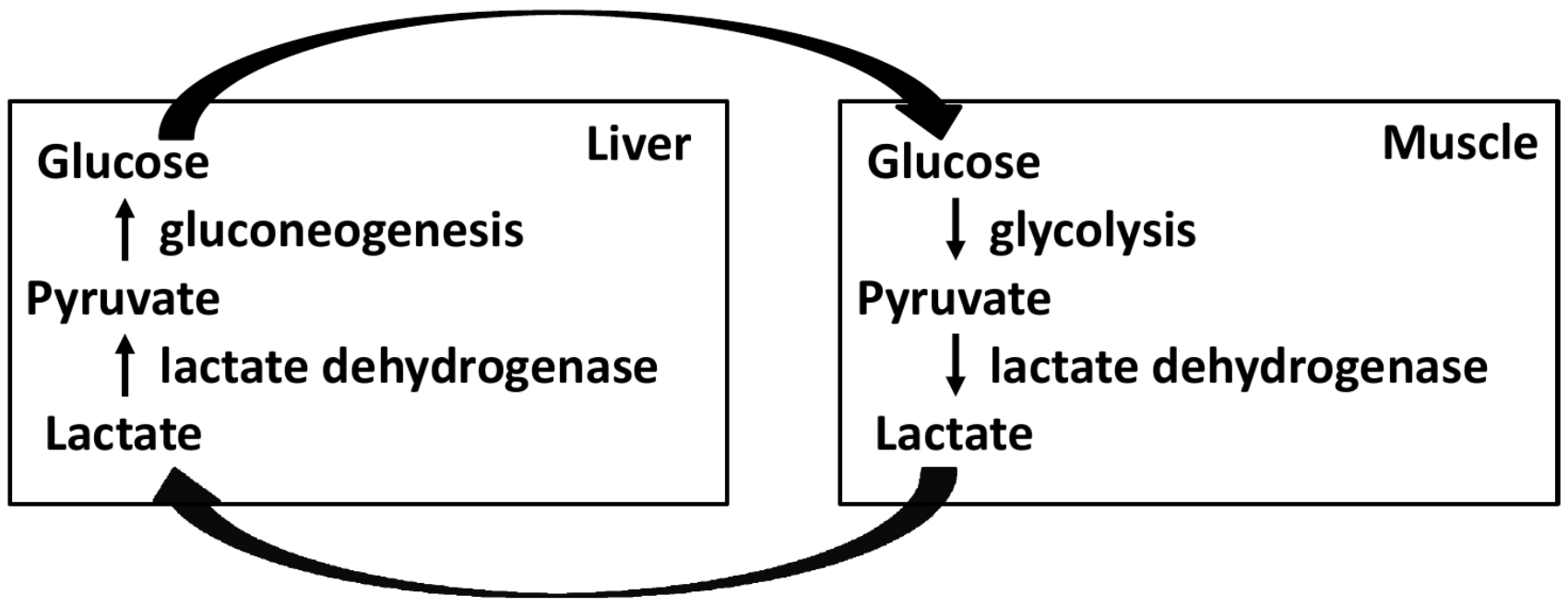

Figure 1: A) The reversible reaction from lactate to pyruvate catalyzed by lactate dehydrogenase. B) The Cori cycle: the liver recycles the lactate produced by the muscle into glucose which fuels the organs, including the muscle. 
This is a post-peer-review, pre-copyedit version of an article published in Metabolic Brain Disease. The final authenticated version is available online at: http://dx.doi.org/10.1007/s11011-014-9573-9

A

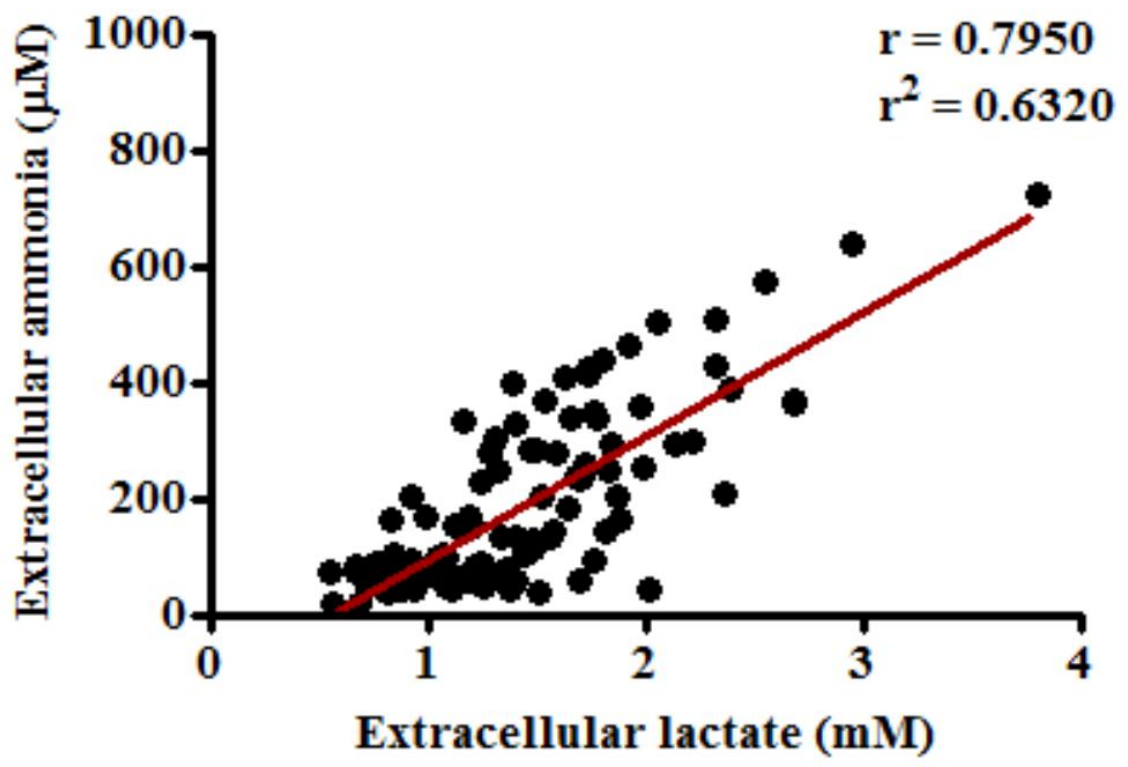

B

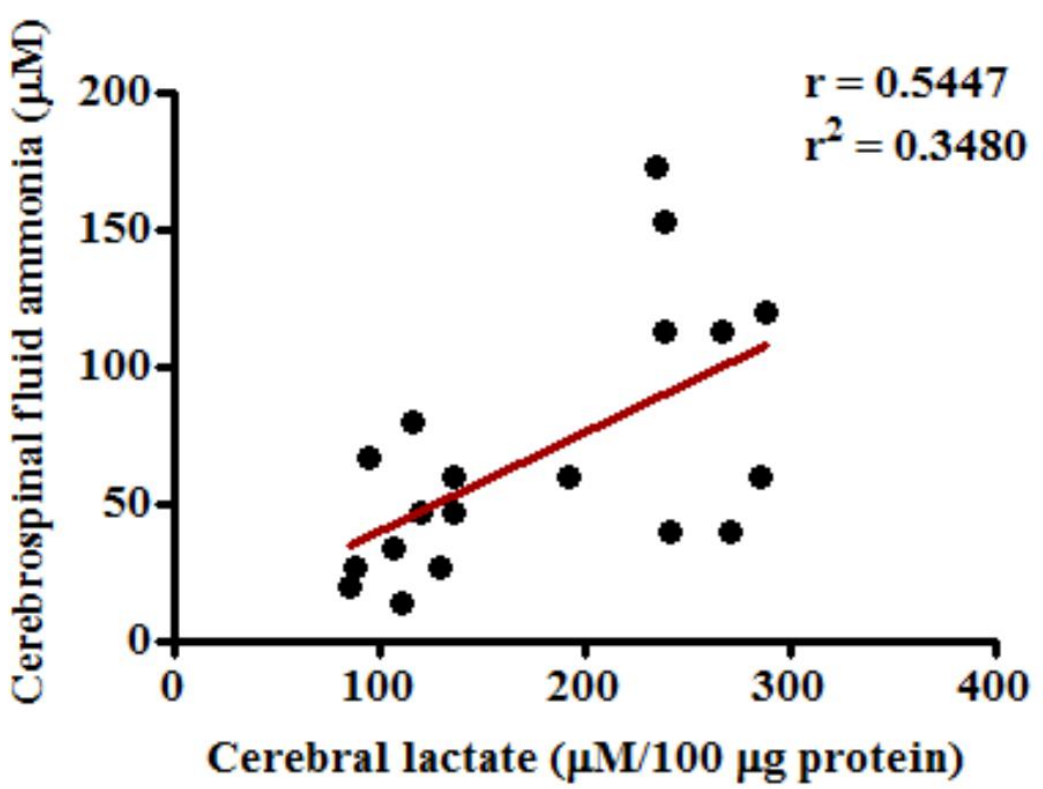

Figure 2: Correlations between cerebral ammonia and lactate during acute liver failure and chronic liver disease. A)

Correlation between cerebral extracellular ammonia and lactate (obtained by microdialysis) in pigs with acute liver failure induced by liver devascularisation. B) Correlation between cerebrospinal fluid ammonia and cerebral tissue lactate in rats with chronic liver disease induced by bile-duct ligation (after Rose et al. 2007; Bosoi et al. 2014). 
This is a post-peer-review, pre-copyedit version of an article published in Metabolic Brain Disease. The final authenticated version is available online at: http://dx.doi.org/10.1007/s11011-014-9573-9

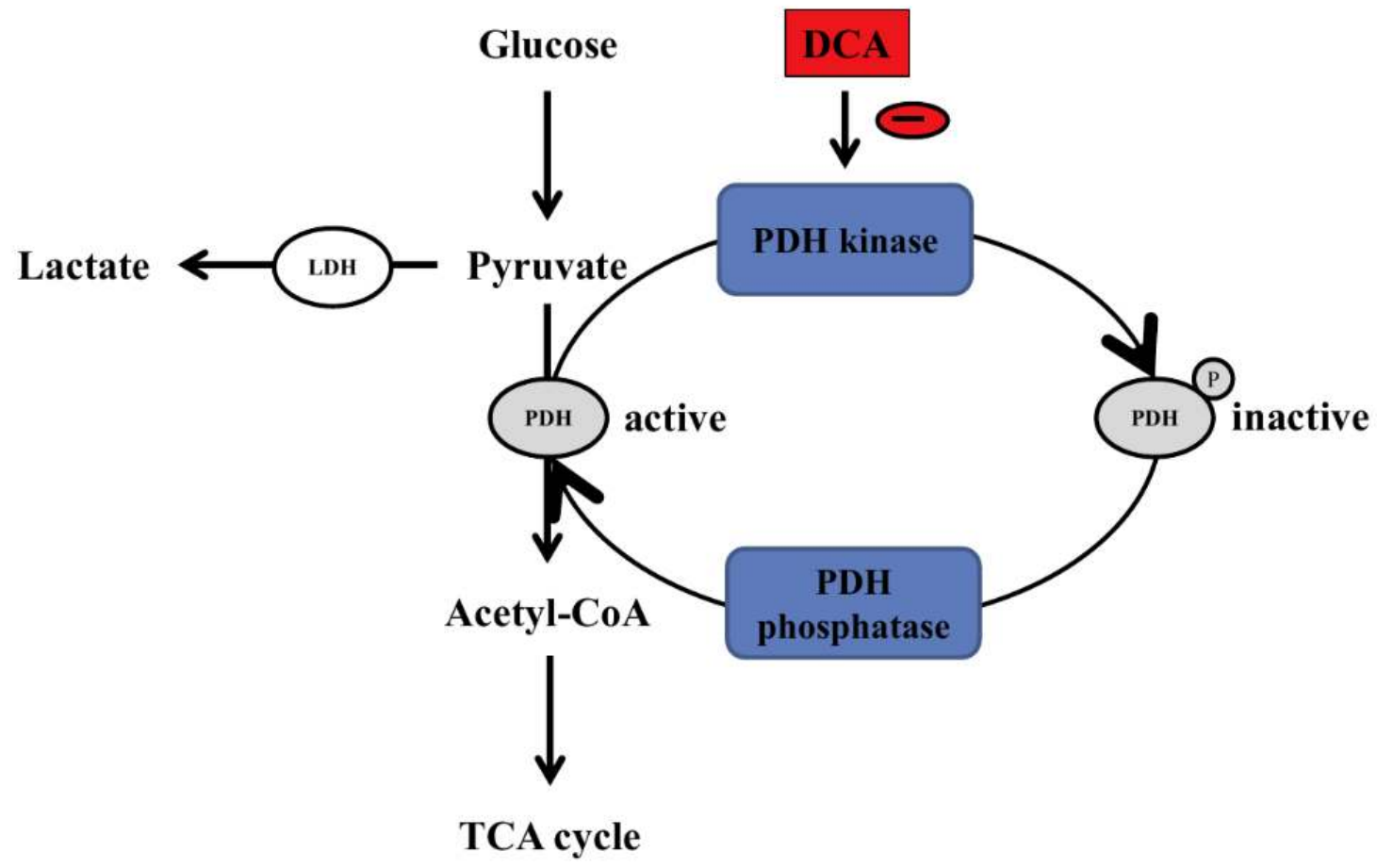

Figure 3: Mechanism of action of dichloroacetate (DCA). Normally, pyruvate dehydrogenase (PDH) activity is regulated by a PDH kinase. This inhibits PDH activity by phosphorylating it (P). As a consequence, pyruvate flux into the tricarboxylic (TCA) cycle is maintained at a basal level and pyruvate is available for lactate dehydrogenase (LDH) which converts it into lactate, allowing lactate synthesis. DCA inhibits the PDH-kinase, therefore PDH is activated and the pyruvate flux into the TCA cycle increases, shifting the LDH toward pyruvate production thus decreasing lactate synthesis. 